Revue

Revue de l'histoire des religions

de l'histoire des religions

\title{
Patrick CABANEL, Entre religions et laïcité. La voie
}

française : $\mathrm{XIX}^{e}-\mathrm{XX} \mathrm{X}^{e}$ siècles

Toulouse, Éditions Privat, 2007, 315 p., 24 cm, $19 €$.

\section{Nicolas Piqué}

\section{OpenEdition}

\section{Journals}

Édition électronique

URL : http://journals.openedition.org/rhr/7313

DOI : $10.4000 /$ rhr.7313

ISSN : 2105-2573

\section{Éditeur}

Armand Colin

\section{Édition imprimée}

Date de publication : 1 décembre 2009

Pagination : 669-670

ISBN : 978-2200-92592-5

ISSN : 0035-1423

Référence électronique

Nicolas Piqué, «Patrick cabanel, Entre religions et laïcité. La voie française : $x i x^{e}-x x^{e}$ siècles 》, Revue de I'histoire des religions [En ligne], 4 | 2009, mis en ligne le 15 mars 2011, consulté le 22 septembre 2020. URL : http://journals.openedition.org/rhr/7313 ; DOI : https://doi.org/10.4000/rhr.7313

Ce document a été généré automatiquement le 22 septembre 2020

Tous droits réservés 


\section{Patrick CABANEL, Entre religions et laïcité. La voie française : $\mathrm{XIX}^{e}-\mathrm{XX} \mathrm{X}^{e}$ siècles}

Toulouse, Éditions Privat, 2007, 315 p., 24 cm, $19 €$.

Nicolas Piqué

\section{RÉFÉRENCE}

Patrick CABANEL, Entre religions et laïcité. La voie française : XIX $-\mathrm{XX} \mathrm{X}^{e}$ siècles, Toulouse,

Éditions Privat, 2007, 315 p., 24 cm, $19 €$.

1 L'analyse que propose P. Cabanel de la laïcité est proprement historique. Pourquoi une telle affirmation, redondante au regard de l'inscription disciplinaire universitaire de l'auteur? Principalement en raison de la caractéristique des études concernant la laïcité, la diversité disciplinaire de leur approche. Certains auteurs ont décidé d'écarter les faits pour s'en tenir à l'étude de la cohérence conceptuelle; tel est le cas, entre autres, du dernier livre de C. Kintzler, Qu'est-ce que la laïcité ? (Vrin, 2007). Le choix de P. Cabanel est donc différent. Son principal apport réside dans l'analyse du détail de l'avènement contourné de la laïcité en France, tant sur le long terme qu'au moment du vote de la loi en 1905.

2 Recueil d'articles, son livre propose trois regroupements, le premier étudiant «le temps long de la question religieuse ", le second resserrant la focale autour du " trentennio laïcisateur (1882-1910) », le dernier s'intéressant à l'exportation de la laïcité.

3 L'un des intérêts principaux de cet ensemble réside, outre la clarté de l'exposition, dans la volonté de présenter l'histoire de la laïcité en France dans toute sa complexité. Cela amène l'auteur à proposer, dans le premier article, une grille chronologique, où il propose de superposer aux trois seuils de laïcisation de Jean Baubérot une approche plus longue selon laquelle tous les siècles « la France change de solution à la question 
religieuse ouverte par l'implantation définitive de la Réforme » (p. 18). Les analyses du détail du choix de la séparation sont traitées dans deux articles de façon précise, montrant une nouvelle fois la complexité du processus législatif, suite d'hésitations et de remaniements. Une autre analyse de détail, mais dont l'enjeu est d'importance pour l'appréciation de la laïcité française au-delà de la radicalité revendiquée de ses principes, réside dans la grille proposée p. 194 faisant la synthèse à la fois des accommodements laïques spontanés, des attaques catholiques et du bilan de ce que l'auteur appelle les «tempéraments » de la loi de 1905. Cette loi fut à la fois le résultat d'une histoire longue, mais aussi d'hésitations et d'ouverture dans les années de part et d'autre de 1905. P. Cabanel dresse de la sorte un tableau nuancé de cette loi, loin de l'image radicale de séparation qui lui est habituellement associée.

4 On peut regrouper une partie des autres articles en les rapportant à « la difficulté de l'apprentissage, par l'État, du pluralisme et de la neutralité » (p. 130). Il s'agit d'abord de l'analyse de la «violence républicaine » (p.111), du combisme en particulier, mais aussi de la période des inventaires, ou de celle de l'épisode de l'expulsion des congrégations ; la même difficulté se retrouve dans l'analyse de l'application complexe de la loi dans les colonies. Enfin, quelques articles proposent des analyses plus circonscrites, mais souvent passionnantes, comme l'étude portant sur le «contrôle de la voie publique ». La question des signes, sur laquelle se concentrent les débats sur la laïcité depuis une quinzaine d'années, y acquiert une profondeur de champ appréciable : «Au moins l'histoire peut-elle apprendre aux protagonistes des querelles d'aujourd'hui que les causes qu'ils épousent ont un passé parfois lointain » (p. 59).

5 Un regret pour finir, concernant l'emploi des notions de "violence républicaine ", ou de haine démocratique, reprises à Jean Baubérot. On aurait aimé que l'historien, soucieux par ailleurs de produire une analyse contextualisée et nuancée, rapporte cette supposée haine à la violence symétrique, sinon originelle, des adversaires catholiques de la République, dont il rappelle d'ailleurs quelques-uns des mots d'ordre dans l'un de ses articles, consacré aux «Catholiques sous la République» (par exemple p.129). Lorsque l'on se souvient des positions odieusement antisémites de certains courants catholiques publiquement influents lors de l'affaire Dreyfus, les réactions républicaines prennent une tout autre signification. Mais cette dernière réserve n'obère en rien l'intérêt de la lecture de cet ouvrage.

\section{AUTEURS}

\section{NICOLAS PIQUÉ}

Université Grenoble I (IUFM). 